University of Rhode Island

DigitalCommons@URI

Open Access Dissertations

1994

\title{
Quantitative EEG Effects Due to Task Related Processing of Lateralized Auditory Continuous Performance Tests, Separate from Attentional and Motor Components of the Tasks
}

Sherri M. Gold

University of Rhode Island

Follow this and additional works at: https://digitalcommons.uri.edu/oa_diss

\section{Recommended Citation}

Gold, Sherri M., "Quantitative EEG Effects Due to Task Related Processing of Lateralized Auditory Continuous Performance Tests, Separate from Attentional and Motor Components of the Tasks" (1994). Open Access Dissertations. Paper 1046.

https://digitalcommons.uri.edu/oa_diss/1046

This Dissertation is brought to you for free and open access by DigitalCommons@URI. It has been accepted for inclusion in Open Access Dissertations by an authorized administrator of DigitalCommons@URI. For more information, please contact digitalcommons-group@uri.edu. 
QUANTITATIVE EEG EFFECTS DUE TO TASK RELATED PROCESSING OF LATERALIZED AUDITORY CONTINUOUS PERFORMANCE TESTS, SEPARATE FROM ATTENTIONAL AND MOTOR COMPONENTS OF THE TASKS BY

SHERRI M. GOLD

A DISSERTATION SUBMITTED IN PARTIAL FULFILIMENT OF THE REQUIREMENTS FOR THE DEGREE OF
DOCTOR OF PHILOSOPHY

IN PSYCHOLOGY 
Abstract

Quantitative EEG data were obtained for 22 male college students during a Resting condition and during performance of three continuous performance tests (CPT) that differed in the demands on linguistic processing. Previous EEG studies from our laboratory have indicated a relationship between left hemisphere beta power and performance of an auditory CPT that requires processing of phonetic stimuli. The participant listens to a series of letters and responds by pressing a button whenever the same letter is repeated twice in a row. This study was designed to test the hypothesis that left hemisphere EEG beta may reflect processing of language information. In this study our previous experimental protocol was repeated with the addition of a CPT that is completely non-verbal (tone task), as well as one that makes greater demands upon language processing (word task) then the letter task. Additionally, many EEG studies of cognitive function employ tasks that require a motor response. Gevins (1980) has cautioned researchers that many EEG effects that are interpretted as due to cognitive processing 
may be confounded by motor effects. In this study, hand use was manipulated i.e., participants performed each CPT with their left hand and with their right hand. Performance data were collected for percent correct responses (hits), reaction time for hits, and percent comission errors (false alarms). A repeated measures MANOVA was performed for performance which resulted in a significant condition effect. It was concluded that the three CPTs differed in task difficulty, which interacted with all the variables. A repeated measures ANOVA was performed on beta2, beta1 and alpha power scores at eight bipolar sites in four regions. Predictions for beta2 were not supported. Findings for the alpha waveband were in accordance with findings reported in the literature i.e., increases in brain activation are associated with decreases in EEG alpha power. Alpha was greater in the left hemisphere FT and $T$ regions during the tone task than during the word task. These findings are consistent with the expectation that the tone task would require less processing demands of the language specialized left hemisphere than the word task would. A significant 
Hand used $\mathrm{x}$ Hemisphere $\mathrm{x}$ Region interaction was observed for alpha. A Hand used $x$ Hemisphere follow up test was significant in the FT region. Compared to left hand use, when using the right hand the left hemisphere is activated and the right hemisphere is idle (deactivated). Compared to right hand use, when using the left hand the right hemisphere is activated and the left hemisphere is idle. This finding replicates a similar result found in this lab and by previous researchers (see text). Evidence is provided from this study that, at least for the alpha waveband, our CPT/EEG procedure is sensitive to variations in cognitive and motor processes. Possible applications are discussed. 
Table of Contents

Abstract. . . . . . . . . . . . . . . . . . ii Table of Contents. . . . . . . . . . . . . . . . . v List of Tables . . . . . . . . . . . . . . . vi List of Figures. . . . . . . . . . . . . . . . vii Introduction. . . . . . . . . . . . . . . . . . . 1 Rationale. • . . . . . . . . . . . . . . . . 7 Hypotheses and Predictions. . . . . . . . . . . . . . . 9 Methods . . . . . . . . . . . . . . . . 10 Subjects . . . • . . . . . . . . . . . 10 Pencil and Paper Questionnaires. . . . . . . 10 Apparatus . . . . . . . . . . . . . . . . 11 qEEG Procedures and Measures. . . . . . . . . . 11 CPT Conditions. . . . . . . . . . . . . . . 12 General Procedures. . . . . . . . . . . 13 Performance Measures. . . . . . . . . . . . . 15 Results. • . . . . . . . . . . . . . . . . 16 Discussion. . . . . . . . . . . . . . . . . . 24 Conclusion. . . . . . . . . . . . . . . . . . 31 Appendix A. . . . . . . . . . . . . . . . . . 33 Appendix B. . . . . . . . . . . . . . . . . . . . . 40 Bibliography. . . . . . . . . . . . . . . . . 53 
List of Tables

Table 1. Mean hit rate, reaction time (RT), and false alarm (FA) rate for 22 right handed males during performance of letter, tone, and word tasks using the left hand and the right hand.

Table 2. Mean absolute power and standard deviation for beta2, betal, and alpha $\log _{10}$ for 22 males at eight electrode sites for each level of task (tone, letter, word) for performance with the left hand and the right hand.

Table 3. Mean absolute power and standard deviations for beta2, beta1, and alpha $\log _{10}$ for 22 right handed males at eight electrode sites for a baseline resting condition. 
List of Figures

Figure 1 .

Beta $2 \log _{10}$ Task by Hand used by

Hemisphere at each region

Figure 2. Beta2 $\log _{10}$ FT region Task by Hemisphere

Figure 3 .

Alpha $\log _{10}$ Task by Hand used by Hemisphere at each region

Figure 4 . Alpha $\log _{10}$ FT region Task by Hemisphere

Figure 5 . Alpha $\log _{10} \mathrm{~T}$ region Task by Hemisphere

Figure 6 . Alpha $\log _{10}$ FT region Hand used by Hemisphere 
Introduction

In previous studies from our laboratory we obtained EEGs of college students during a baseline resting condition and during performance of an auditory continuous performance test (CPT) that involved phonetic processing. The CPT required the participant to listen to a series of rapidly presented alphabet letters and to press a button whenever the same letter was repeated twice in a row. These studies have revealed that fast frequency EEG (beta1 and beta2 frequency bands) recorded over language areas of the left hemisphere changed in ways that are consistent with the hypothesis that it is a reflection of phonetic processing of the CPT stimuli. Summarized below are findings from our lab for absolute power and percent asymmetry of various EEG frequency bands, with emphasis on fast frequency EEG.

Generally, across studies beta bands increase from the Resting to the CPT conditions in all regions i.e., frontal (F), fronto-temporal (FT), temporal (T) and temporal-occipital(TO), particularly in the temporal region and in the left hemisphere. Power in posterior alpha bands decreases from Resting-to-CPT conditions. 
In one study, twentyseven subjects who maintained high response accuracy over time were compared to twentyseven subjects who showed a performance decrement. The group that maintained high accuracy had overall greater levels of beta, and less alpha and posterior theta. FT and $\mathrm{T}$ beta remained level in this group over the ten minute CPT but declined significantly in the group that showed a performance decrement. It was concluded that FT and T beta was the best indicator of performance errors and possibly a measure of language processing (Valentino et al., 1993).

In another study, during a CPT condition in which left and right handers responded to targets with their left hand (CPTL), beta was greater in the left hemisphere than in the right hemisphere F, FT, and T regions. Fronto-temporal and temporal beta2 asymmetry was greater toward the left hemisphere during CPTL than at Resting or when subjects responded with their right hand (Gold et al.,1993). It was hypothesized that beta reflected cognitive processing of the phonetic stimuli used in the task and that performance with the left hand enhanced the ability of the left hemisphere to perform the language task by freeing up left hemisphere processing resources (e.g. see Friedman and Polson, 1988) required to regulate responding in the right hand condition. 
A principal components analysis (PCA) was performed on EEG data from over 100 participants to determine if the resulting components could explicate neural systems underlying brain-behavior relationships. The PCA revealed six orthogonal components. One was a left hemisphere beta component that may reflect cognitive processing of the phonetic CPT signals. Another was a right hemisphere beta component that may reflect processing related to attentional aspects of the task (Weiler, 1993; Arruda, 1994).

Other authors have also argued that EEG beta in the left hemisphere reflects cognitive processing of language information. For example, Papanicolaou et al. (1986) had participants perform two linguistic (phonetic and semantic) and one acoustic (intensity) target detection task during collection of eyes closed EEG. A left greater than right hemisphere beta asymmetry was observed when participants performed the semantic target detection task. A similar but less consistent effect was observed for the phonetic task. Hemispheric differences were not observed for the acoustic task. Since no effect for alpha was found it was concluded that the beta waveband was a sensitive index of task dependent hemispheric processing . 
Ray and Cole (1985) studied EEG during a variety of tasks that differed in their demands upon attention, language and spatial processing. Ray and Cole reported that EEG beta wavebands measure cognitive processing and the alpha waveband reflects the attentional demands of a task .

Lauter (1992) used an EEG measure along with a behavioral measure (dichotic listening) in examining hemispheric lateralization for a three-tone pattern task and a consonant-vowel syllables task. The three-tone pattern task consisted of three pure tones presented with a 200-ms inter-onset interval between each tone. The three frequencies were arranged in six different patterns (e.g., low-medium-high). A three tone melody was presented to the attended ear, while a repetition of three tones was presented to the opposite ear as a "mask". Lauter wanted to determine whether there were physiological correlates of lateralized effects previously shown in dichotic listening tasks. Seven females underwent a resting baseline condition before monaural presentation of consonant-vowels to the left ear. This was followed by monaural presentation to the right ear and dichotic presentation in which the participant first attends to the message in the right ear then the left ear. This sequence was followed for the 
three tone pattern task. The same presentation sequence was followed for an EEG session, however, accuracy data was not collected. Results for the dichotic test were as expected: a right ear-left hemisphere advantage was observed in the syllables task and the opposite was seen for the tone task. EEG analysis was limited to power asymmetry in the beta band temporal region. Hemispheric asymmetries observed in the dichotic listening measure were replicated in the EEG measure.

On the basis of previous findings from our lab we attribute the Resting-to-CPT beta increase seen between resting and $\mathrm{CPT}$ conditions at the frontal, frontotemporal and temporal regions in the left hemisphere as task dependent processing of the phonetic signals. The addition of a non-verbal condition that engages right hemispheric mechanisms and a language condition that requires both semantic access and phonetic processing, would clarify whether the task dependent left hemisphere beta effect we have observed is related to language processing.

The present study is designed to test the hypothesis that left hemisphere EEG beta may reflect cognitive processing of language information. When a task is used that engages cognitive processing in the right hemisphere, it is expected that the left hemisphere beta 
effect would be reversed or negated. Previous studies of cognitive processing on EEG have conventionally explored the alpha waveband. Decreases in alpha power correspond to increases in brain activation. Based on previous qEEG, PET and dichotic listening studies of cognitive function, lateralized effects have been observed.

\section{EXAMPLES OF TASKS THAT LATERALIZE COGNITIVE FUNCTION}

Kinsbourne's theory of hemispheric specialization (1983) proposed that the brain is comprised of interconnected functional neural systems. Tasks that share functional space are more likely to conflict because their functional systems overlap. Cerebral regions that are highly interconnected would lend themselves to successive use to allow the tasks to be completed efficiently. Whereas, regions with disparate functional cerebral distance may be better able to perform tasks simultaneously.

\section{Dichotic listening studies}

Sidtis (1978) developed a complex tone test in which a dichotic pair of tones was presented to participants followed by a probe tone one second later. The complex tones were comprised of the fundamental frequency of one of the eight notes in the octave between $\mathrm{C} 4$ and $\mathrm{C5}$ of the 
major scale (i.e., 264-528 $\mathrm{Hz}$ ) and the second and third harmonics of that note. The task was to move a lever to a yes or no position to indicate whether or not the probe matched in pitch to the dichotic tone. Sidtis studied 24 males and females on accuracy and reaction time measures and found a significant right hemisphere-left ear advantage. In another paper, Sidtis (1980) found no ear advantage for pure tones. These findings support a behavioral effect for a right hemisphere processing of complex tones. This is compatible with the generally held belief that, at least for right handers, non-verbal auditory discriminations depend upon right hemisphere activation. Dichotic listening studies generally show a right ear advantage for verbal stimuli and a left ear advantage for complex (as opposed to pure) tones.

\section{PET studies}

Petersen et al., (1989) examined subjects' blood flow changes during performance of tasks involving "lexical (single-word) processing". A subtraction technique was utilized in which the blood flow changes during a task condition was subtracted from a baseline condition in order to separate out any effects that are not specific to the task. In one condition subjects' passively listened to words presented aurally; bilateral 
regions near the posterior temporal lobe were activated. In the left hemisphere, areas in the anterior and inferior temporal cortex were activated, as well as the right hemisphere lateral temporal cortex. These areas may constitute a secondary auditory area. Additionally, the left hemisphere temporoparietal cortex near the supramarginal and angular gyri (Wernicke's area) were activated. Petersen et al., attributed activation of the anterior superior temporal cortex in the left hemisphere, the left hemisphere temporoparietal cortex and the right hemisphere lateral temporal cortex, to phonological processing or storing of the spoken word in the form of a "sound".

A second condition required the subject to listen to a noun and then say aloud a semantically appropriate verb. During performance of this task additional activation was observed in the left hemisphere inferior prefrontal cortex and the cingulate cortex. Petersen et al., attributed the activation to the semantic associations, syntactic processing, higher order attention and nonspecific arousal required to perform the task.

Petersen et al., developed a cognitive-anatomical model for processing of aurally presented single words. The network is as follows. Early auditory processing 
occurs in the primary auditory cortex. The information is then coded phonologically in the left temporoparietal cortex. Processing for semantic associations occurs in the left hemisphere anterior and inferior frontal cortex. Information travels parallel pathways to the supplementary cortex, sylvian cortex and the left hemisphere premotor area for articulatory preparedness before travelling to the motor cortex and finally motor output. We expect the EEG montage we are using will record activity in the areas delineated by Petersen et al. that occur as a result of processing of the language task.

\section{Rationale of Present study}

This study was designed to test the hypothesis that the left hemisphere fast frequency EEG effects we see during our CPT are related to some aspect of the phonetic processing of the CPT letter stimuli. To do this, our previous experimental protocol was repeated with the addition of a CPT that is completely non-verbal, as well as one that makes greater demands upon language processing than the letter task. Introducing a nonverbal task that engages right hemisphere cerebral processing should negate or reverse the left hemisphere beta effects we typically see during the letter task. Furthermore, introducing a task that is specifically 
designed to engage semantic processing may enhance these effects. Since our CPT task may involve only phonetic processing and may be a more neutral task with respect to engagement of hemispheric processing, using a semantic processing task should help us to confirm that the CPT engages mechanisms involved in language processing.

The semantic task was designed to be similar to the letter CPT. The participant listened to a series of nouns from four categories and indicated by a button press when two nouns from the same category follow directly one after the other. It was expected that the addition of a task involving both phonetic and semantic processing would enhance the left hemisphere beta effect. To further test the left hemisphere beta effect a nonverbal condition was added that engages right hemispheric processing mechanisms. This task involved presentation of a series of tones and the participant was instructed to press a button whenever the same tone was repeated twice in a row.

To date, many of the studies of EEG and cognitive function contain methodological problems. Among the problems are small sample size, no baseline condition to compare treatment conditions, a lack of adequate control over cognitve variation (tasks are too complex, or completely different from one another which makes 
comparison across tasks difficult), and hand use is not manipulated.

This study addressed many of the methodological problems that plague studies of cognitive function. The tasks were simple vigilance tasks presented aurally and similar in difficulty. Hand use was manipulated (Gevins et al. 1980) and counterbalanced to control for effects due to order of presentation.

\section{Hypotheses and Predictions}

Hypotheses are in accordance with current literature and are as follows:

1) Language functions are left lateralized for most people.

2) Non-verbal tasks activate right hemispheric mechanisms .

3) A semantic (word) task places greater demands upon left hemisphere processing than a phonetic (letter) task. 4 ) EEG beta power is related to information processing. Predicted results are as follows:

1) It was predicted that during the word and letter tasks beta would be greater in the left hemisphere than the right hemisphere.

2) It was additionally predicted that left hemisphere beta would be greater during the word task than the 
letter task and left hemisphere beta would be greater during the letter task than the tone task.

3) Beta power was predicted to be greater in the right hemisphere than the left hemisphere during the tone task. 4) Right hemisphere beta was predicted to be greater during the tone task than the letter and word tasks. 5) During the letter and word tasks, beta power in the left hemisphere was predicted to be higher when the left hand was used than when the right hand was used. During the nonverbal, tone processing task, beta power was predicted to be higher in the right hemisphere when the right hand was used than when the left hand was used. 6) Performance accuracy during the word and letter tasks was predicted to be higher during CPTL (left hand used) than during CPTR (right hand used). Performance accuracy during the tone task was predicted to be higher in CPTR than CPTL.

Method

Subjects

Participants were recruited from the psychology 113 course. Participation in research was required in 
this course. Participants were drawn from a group previously run under an IRB approved protocol by $\mathrm{Dr}$. Dominic Valentino. The sample consisted of 22 males aged 18-27 (mean age $=21.6$, standard deviation $=2.78$ ) with no history of birth stress or loss of consciousness due to a head injury.

Pencil and Paper Questionnaires

Participants were asked to fill out several questionnaires (see Appendix A); these included modified versions of the Edinburgh Handedness Inventory, the Michigan Alcohol Screening Test and an additional questionnaire designed to screen for depression, substance abuse, head injuries, birth stress, medication, and caffeine use. Right handedness was determined by hand used to write with as well as a score of 10 out of a possible 13 points on the Edinburgh Handedness Inventory. Apparatus

A Sentinal 8 data acquisition system manufactured by Axon Inc., Maupauge NY was used to amplify, digitize, and measure participants' brain waves. The digitized measures were subjected to a spectral analysis by Fast Fourier Analysis on an IBM compatible AT style computer. A second IBM compatible computer was used to present the three continuous performance tests and to record reaction time and performance data. The participants' listened to 
the stimuli through head phones placed over their ears and held a hand held clicker to indicate a target by pressing the button.

qEEG Procedures and Measures

Recordings were from eight bipolar sites: Fp1-F7, Fp2-F8 (frontal region); F7-T3,F8-T4 (fronto-temporal region); T3-T5, T4-T6 (temporal region); T5-01, T6-O2 (temporal-occipital region). A ground electrode was placed in the middle of the forehead. Impedance on all channels was 10 Kohms or less. Low- and high-pass filter settings were $0.5 \mathrm{~Hz}$ at $18 \mathrm{~dB} /$ octave rolloff and $50 \mathrm{~Hz}$ at $24 \mathrm{~dB} /$ octave rolloff; gain $=10,000$. Signals were digitized (sampling rate $=200 / \mathrm{sec}$, with 12 bit precision) and a spectral analysis was performed (FFT point every $0.4 \mathrm{~Hz}, 2.5 \mathrm{sec}$ segments). Absolute power was calculated for delta $(1-3.5 \mathrm{~Hz})$, theta $(3.5-7.5 \mathrm{~Hz})$, alpha $(7.5-12.5 \mathrm{~Hz})$, beta $1(12.5-17.5 \mathrm{~Hz})$, and beta2 $(17.5-25.0 \mathrm{~Hz})$. Power values were transformed $(\log 10)$ before analysis in order to obtain Gaussian distributions (Gasser et al., 1982; Weiler, 1992).

\section{CPT Conditions}

Letters. The phonetic task consisted of 24 alphabet letters presented in random order at a rate of $2 /$ second. A target is defined as two consecutive presentations of 
the same letter which occurred approximately every six seconds.

Tones. The tone test (Sidtis, 1980) consisted of eight complex tones that were square waves with fundamental frequencies corresponding to the eight notes in the octave between $\mathrm{C} 4$ and $\mathrm{C5}$ on the major scale (Sidtis, 1980). Each fundamental frequency had its first two harmonics superimposed by a digitized system. The tones were obtained from Sidtis. The tones were presented at a rate of $2 /$ second. A target was defined as two consecutive presentations of the same tone which occurred approximately every six seconds.

Nouns. The semantic task consisted of 20 words from four categories. The four categories were as follows: animal names, people names, numbers and body parts. It was intended that each of the four categories would have the same number of stimuli, but because of poor auditory quality some of the words were not included. The stimuli that were used are as follows: one, two, four, five, six, cat, cow, dog, deer, arm, ear, knee, neck, nose, toe, Ann, Bob, Jim, John, Sue. The words were presented at a rate of $1 / 700 \mathrm{msec}$. This is a slightly slower rate than for the other two CPTs. This rate was chosen in an attempt to equate task difficulty, since pilot studies with the task showed it to be more difficult than the 
other two CPTs. Two consecutively presented words from the same category constituted a target, which occurred approximately every seven seconds.

General Procedure

The participant was given the set of questionnaires upon entering the laboratory. When the questionnaires were completed the participant sat in a comfortable arm chair while the electrodes were applied. The Resting condition occurred first followed by the three tasks. The three task conditions were presented in a counterbalanced order. Hand used to press the button was also counterbalanced during each of the three tasks. In other words, each task was done with the left hand and with the right hand. Participants were given the following instructions for the Resting condition:

Sit with your eyes closed throughout the entire time we are recording. Keep your legs uncrossed with both feet on the floor; try to move as little as possible. First, I am going to record your EEG while you rest. I would like you to relax and pretend you are sitting at home in your most comfortable chair. When I am done with this recording I will walk over to your chair and explain to you how to do the first task. There are three separate tasks that you will perform, each will involve listening to stimuli over the headphones and pressing a button. I will explain each task to you before you begin. I would like you to wear the headphones and hold this hand held clicker now during the resting recording. (At this point I hand the clicker to the participant and put the headphones over the participants ears). Do you have any questions? 
The participant relaxed for approximately two minutes and 45 seconds while a two minute sample of artifact free EEG was collected. This constituted the Resting condition. The participant was then instucted in how to perform the first task (e.g., letters task), as described below.

The first sequence you will listen to will consist of letters of the alphabet that are arranged in random order. Whenever you hear the same letter repeated twice in a row, that is a target. Press the button once. For instance you may hear "a $g$ f $b$ b ", press the button when you hear "bb". You will be told when to begin. The beginning will consist of a short practice session just to make sure you have gotten the hang of it. Upon completion of the practice session, I will ask you if you have any questions. Then I will begin the recording session. When the recording is completed, I will stop the audio and ask you to use you other hand to press the button. Then I will play the sequence again. Remember to keep your eyes closed the entire time. Do you have any questions? I will start the short practice sequence.

The sequence containing the auditory alphabet letters was played and performance data was collected. Fortyfive seconds after the participant began performing the task, two minutes of artifact free EEG was collected. Upon completion of this recording, the participant was instructed to use his/her other hand to do the remainder of the task. The same sequence was presented and after 45 seconds of presentation 2 additional minutes of artifact free EEG was collected. The participant was given the following instructions before presentation of the tone stimuli: 
Place the clicker in your left (right) hand. I am going to play a sequence of tones. Whenever you hear the same tone repeated twice in a row, press the button once. The beginning will be a short practice session just to make sure you have gotten the hang of it and I will ask you if you have any questions. The recording sequence will follow. After I have finished recording your data I will stop the audio and ask you to use your other hand to press the button. Then I will play the sequence again. Remember to keep your eyes closed the entire time.

Data collection was the same as above. The participant changed hand use as above.

Instructions for the word task are as follows:

Place the clicker in your left (right) hand. I am going to play a sequence of nouns. The nouns will come from four different categories. Whenever you hear two nouns from the same category, that is a target. Press the button once. The four categories are as follows: animal names such as cat or dog, numbers such as one or two, peoples'names such as John or Sue and body parts such as nose or toe. An example of what you will hear is as follows:" cat, one, Sue, toe, nose", press the button when you hear "toe, nose". The beginning will be a short practice session just to make sure you have gotten the hang of it and I will ask you if you have any questions. Then the recording session will begin. After completion of data collection, I will stop the audio and ask you to use you other hand to press the button. Then I will play the sequence again. Remember to keep your eyes closed the entire time.

Data collection was the same as above.

\section{Performance Measures}

Performance data: percent correct responses (percent hits), percent comission errors (false alarms) and reaction time for hits were collected for each task condition. Percent hits are calculated as total hits 
divided by total targets (hits plus misses), then multiplied by 100. Percent false alarms are calculated as the number of false alarms divided by the number of stimuli minus the number of targets (hits plus misses), then multiplied by 100. Reaction time was calculated as the time it took the participant to press the button to correctly indicate that a target occurred. The reaction time cutoff for the letter and tone tasks was one thousand milliseconds (one second) and for the word task the reaction time cutoff was one thousand, four hundred milliseconds. If a button press did not occur within the reaction time cutoff a miss was recorded.

Results

Performance Data. A repeated measures multivariate analysis of variance was performed for the variables: condition (letter, tone, and word) $x$ hand used (left, right) for hits, reaction time and false alarms. A significant condition effect was observed $F(2,42)=88.00$, p>.0001. All significant analyses are reported with the Geisser-Greenhouse (GG) correction unless otherwise noted. Tukey Honest Significant Differences (HSD) were calculated at the .01 level of significance. Table 1 shows means and standard deviations for the performance measures . 
Insert Table 1 here

Follow up one way ANOVAs were performed for Condition for each performance measure (hits, reaction time for hits, false alarms). There was a significant Condition effect for hits $F(2,45)=61.94, \mathrm{p}<.0001$. A Tukey HSD test revealed that the percentage of hits was significantly higher for the letter task than for the tone task and performance for tones was significantly better than for words. Performance differences for hand use within a task were not significantly different. There was a significant Condition effect for reaction times $F(2$, $45)=83.82, \mathrm{p}<.0001$. A Tukey HSD determined that reaction times for the letter task and the tone task were faster than for the word task. Reaction times for tones and letters were not significantly different. A Condition effect was also observed for the false alarm rates $F(2$, 33) $=13.78, p=0001$. A Tukey HSD test revealed that the false alarm rate for tones was significantly higher than for words or letters and words had a higher false alarm rate than letters.

EEG Data.

Means and standard deviations for log10 absolute power in beta2, beta1, and alpha at each of the eight 
bipolar sites during tone, letter, and word for the left hand used and right hand used are shown in Table 2 .

Insert Table 2 here

Table 3 shows means and standard deviations for the Resting condition for $\log _{10}$ absolute power in beta2, betal, and alpha at each of the eight bipolar sites.

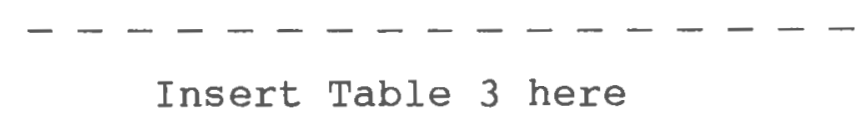

The first analyses of the EEG data were separate four way repeated measures ANOVAs performed for the beta2, beta1, and alpha wavebands. Factors were Task (tone, letter, word), Hand used (left hand, right hand), Region (frontal, fronto-temporal, temporal, occipital), and Hemisphere (left, right).

\section{Beta2}

A significant Task $\mathrm{x}$ Hand used $\mathrm{x}$ Region $\mathrm{x}$ Hemisphere interaction was observed for beta2, $F(3,67)=29.35$, $\mathrm{p}<.0001$ (see Figure 1).

Insert Figure 1 here 
Follow up analyses of Task $\mathrm{x}$ Hand used $\mathrm{x}$ Hemisphere were performed for each region. A Task $\mathrm{x}$ Hemisphere interaction was significant only at the FT region $F(2,42)=3.28, p<.05 \quad(p=.07 \quad G G)$. A significant Task effect in the left hemisphere FT region $\mathrm{F}(2,38)=4.57, \mathrm{p}=.02$, was observed, but not in the right hemisphere. However, a Tukey (HSD) test did not find significant differences between the means (see Figure 2).

Insert Figure 2 here

\section{Beta 1}

No significant interactions were found for betal. A main effect for Region was obtained. A Tukey (HSD) test revealed no mean differences between the four regions at the .0l level of significance.

\section{Alpha}

A significant Task $\mathrm{x}$ Hemisphere $\mathrm{x}$ Region interaction was observed for alpha $\mathrm{F}(3,56)=3.36, \mathrm{p}=.03$ (see Figure 3). Follow up tests revealed significant Task $x$ Hemisphere interactions in FT $[F(2,40)=4.00, p=.03]$ and $T[F(2,42)=3.32, p<.05(p=.05 G G)]$ regions. 
Insert Figure 3 here

For FT alpha a task effect was obtained in the left hemisphere $F(2,33)=6.10, p=.009$ but not in the right hemisphere $F(2,34)=1.68, p=.20$. A Tukey HSD test revealed that the tone condition had greater alpha power than the word condition in the left hemisphere FT region. The mean for the letter condition was intermediate but not significantly different from either tasks (see Figure 4).
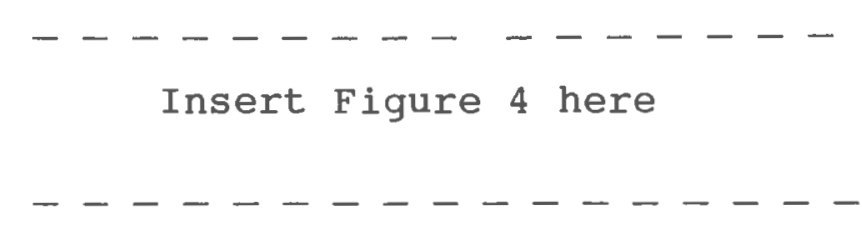

For temporal alpha an effect for task was observed in the left hemisphere $F(1,29)=7.58, p=.005$ and in the right hemisphere $\mathrm{F}(2,34)=3.74, \mathrm{p}=.04$ (see Figure 5). A Tukey HSD test determined that in the left hemisphere $T$ region more alpha was observed in the tone condition than in the word condition, and higher alpha was found in the letter condition than the word condition. In the right hemisphere there were no significant differences between tasks at the .01 level of significance. 
Insert Figure 5 here

A significant Hand used $x$ Hemisphere $x$ Region interaction was also observed for alpha $F(2,49)=5.20$, $p=.007$. A Hand used $x$ Hemisphere simple effects test was performed for each region, but was significant only at the $F T$ region $F(1,21)=7.17, p=.01$. Use of the right hand was associated with decreased left hemisphere (compared to right hemisphere) alpha. However, simple contrasts of Hand used at either hemisphere did not reach significance (see Figure 6).

Insert Figure 6 here

\section{Discussion}

Performance data

Differences in various aspects of performance occurred between the tone, letter and word tasks. These differences were much bigger than was expected on the basis of pilot studies. The differences in performance indicated that the tasks varied in ways other than the planned manipulation of demands on brain mechanisms for language processing. On the basis of percent accuracy and 
reaction time, the word task appeared to be cognitively more difficult than the other tasks. This confounds beta2 since it is well known that beta is affected by task difficulty. Beta increases with task difficulty, i.e. high beta power is associated with tasks that require increased demand on cognitive processing. In this study, the highest beta power was observed during the word task. In order to observe the relationship between beta and cognitive processing of linguistic stimuli, future studies should emphasize that tasks be equated in terms of difficulty. The word task could be made easier by slowing the presentation rate even further or by reducing the number of stimuli or categories. A longer practice session may improve performance. However, these alternatives create additional problems because while equating task difficulty, critical variables may be changed that cause the tasks to require different cognitive processing in addition to the language dimension being manipulated. In other words, to compare task conditions the tasks need to be similar to one another in every way except for linguistic content. This study attempted to equate the tasks in terms of number of stimuli and targets, presentation rate of stimuli and targets, cognitive processing (including that in all three tasks each stimulus was also a possible target), 
memory load, motor output, instructions for task performance and practice sessions.

The tone task had the highest false alarm rate along with an intermediate percent accuracy. This may have been due to low discriminability of the stimuli, which made the task difficult. In future studies, tone sequences could also be arranged so that tones that are similar to one another in frequency and perception are separated. In addition, a larger range of the tone stimuli would alleviate the discriminability problem and help to equate task difficulty.

Based on previous findings from our lab, performance accuracy on letter and word tasks was predicted to be highest when the left hand was used (Gold, 1992). This effect may be explained by Kinsbourne's hypothesis of functional cerebral distance (1983). Mental processes controlled from the same hemisphere interfere with one another since they draw from a common pool of attention. When a participant uses his/her left hand the motor cortex of the right hemisphere is activated, competition for resources is alleviated, and the left hemisphere can best perform language functions. The data in this study did not support this prediction; no differences in performance were related to hand used. However, Figure 1 highlights a nonsignificant but important finding. In 
FT, T and TO regions mean left hemisphere beta 2 was higher during the word/left hand condition than in any other condition. During the word/left hand condition there is presumably the greatest demand for left hemisphere processing of the cognitive (linguistic) aspects of the task, and competition for left hemisphere resources has been alleviated by right hemisphere motor activation. Therefore, an increase in beta would be expected and is observed in the left hemisphere during performance of the word task.

In addition, within tasks there were no order effects for hand used i.e., it did not appear that practice effects influenced performance. Thus, using one hand first to perform the task did not result in improved performance with the other hand.

\section{Beta2}

A significant Task $\mathrm{x}$ Hand used $\mathrm{x}$ Region $\mathrm{x}$ Hemisphere interaction was obtained for $\log _{10}$ beta2 power. In the FT region, a condition effect was observed in the left hemisphere. This is depicted in Figure 2. However, pairwise differences of the means did not reach significance. Left hemisphere beta2 was lower for the letter task than the word task as predicted. Beta2 was also lower for the letter task than the tone task, however, which was not predicted. 
Beta2 in the FT and $\mathrm{T}$ regions showed differential hemispheric effects. However, the left hemisphere was predicted to have greater beta2 power than the right hemisphere during the word and letter tasks. This prediction was not supported.

Predictions for the tone task were not supported. It was hypothesized that during performance of the tone task, processing demands in the left hemisphere would be lower than for the other two tasks and would be higher in the right hemisphere than the other two tasks. This effect was predicted to be directly reflected in beta2 power. However, beta2 power was the same or greater during the tone task than the letter task regardless of hemisphere or hand used.

\section{Alpha}

A Task $\mathrm{x}$ Hemisphere $\mathrm{x}$ Region interaction was obtained for alpha. Figure 3 depicts significant Task $\mathrm{x}$ Hemisphere interactions at the FT and $\mathrm{T}$ regions. Alpha power was greater in the left hemisphere FT and $T$ regions during the tone task than during the word task. These findings are consistent with the expectation that the tone task would require less processing demands of the language specialized left hemisphere than the word task would. It has been established in the literature that increases in brain activation are associated with 
decreases in EEG alpha. During cognitive processing of a task alpha will decrease from a baseline resting condition as well as decrease more in the hemisphere engaged in processing the task.

In previous research from our lab, we have found only the expected significant alpha decrease from resting to task conditions and a motor effect when the right hand is used to perform a task (see below). However, in this study alpha behaved in important ways i.e., alpha behaved as beta was predicted to behave. In fact, the alpha effects observed in this study would be predicted by many EEG researchers since much of the previous EEG literature on hemispheric differences in cognitive processing has been based on findings in the alpha frequency bands (Provins \& Cunliffe, 1972; Butler \& Glass, 1974; Empson, 1982; Galin, Ornstein, Herron, \& Johnstone, 1982). The letter task may be less lateralized than the word task in terms of cognitive function because the word task required semantic processing in addition to phonetic processing. Additionally, the word task had the lowest hit rate and the longest reaction time of the three tasks. The word task was the most cognitively demanding task requiring more general attentional resources than the tone and letter tasks. Therefore, alpha would be 
lowest during the word task and highest during the letter task.

\section{Motor effects due to hand used}

A significant Hand used $x$ Hemisphere $x$ Region interaction was obtained for alpha. Follow up tests of Hand used $x$ Hemisphere reached significance only in the FT region. Simple contrasts were not significant. Inspection of Figure 6 reveals that when the right hand was used there was more of a difference between hemispheres, with the left hemisphere most desynchronized. This effect is measured across tasks. Thus, one could conclude that the significant interaction was not a result of the cognitive demands of the CPT tasks, but instead was caused by the motor demands, use of the right hand, which perhaps desynchronized alpha in the left hemisphere. A similar result has been previously observed in the lab (Gold, 1992) and by previous researchers (see Rebert \& Mahoney, 1978; Kristeva, Keller, Deeke, \& Kornhuber, 1979; Autret, Auvert, Laffont, \& Larmande, 1985; DeToffel, Autret, Markabi, \& Roux, 1990). Gevins et al. (1980) has suggested that the motor response required in many tasks can complicate interpretation of effects of cognition on EEG. Therefore, by manipulating hand use, effects due to 
motor response can be separated from effects due to the cognitive demands of the task.

\section{Conclusions}

Most of the predictions in this study were not supported by the data. This is probably because task difficulty interacted with all of the variables. Findings for the alpha waveband were in accordance with what would be expected and a motor effect was observed that replicated previous findings from our lab.

Previous findings from our lab have demonstrated a left hemisphere beta effect during processing of phonetic stimuli (i.e., the letter task). This effect was not replicated in this study. There are several reasons that may explain this occurrence. First of all, and perhaps most importantly, this study altered the experimental protocol that had been established in the lab. Instead of using one or two conditions, this study incorporated many conditions utilizing three separate tasks. In addition, some past studies in the lab have looked at performance over a longer period of time than in this study. It may be the case that when the tasks are performed over a longer period of time a different EEG pattern will emerge than is present initially. This study could not extend the length of each task because 
there were already many task conditions. It may be better to use fewer tasks and have participants perform the tasks for a longer period of time than was used in this study

Secondly, our lab has moved to a new location and along with changing rooms other factors have been altered that may affect the results. For example, participants now listen to computer generated stimuli over headphones. Previously the same stimuli were presented from a tape recorder through a speaker above the participant's head. Evidence is provided from this study that, at least for the alpha band, our CPT/EEG procedure may be sensitive to variations in cognitive processes. As such it may also be sensitive to neurological or cognitive impairments in these processes. Thus, it may be used as an adjunct to neurophysiological and neuropsychological assessment. Some clinical applications include monitoring recovery after brain trauma or metabolic disorder, the experimental development of drugs by monitoring sedating or stimulant side effects, and for determination of appropriate dosage levels of psychoactive drugs during treatment. 
Appendix A 
Group___ \#

Informed Consent

Subject/Patient Name

Institution

Location

I have been asked to take part in a research project (described below). I should feel free to ask questions of the researcher. If I have more questions later, Dr.

Valentino, the person mainly responsible for the study (792-4233), will discuss

them with me. I may participate in the study or I may change my mind and withdraw at any time by contacting Dr. Valentino (792-4233). I understand that I will not receive payment for my participation, nor will I be penalized in any way if I withdraw.

Researchers at the University of Rhode Island Dept. of Psychology are conducting a study to observe changes in the electroencephalogram (EEG) during different tasks. As part of this study, I will be asked to sit for an EEG recording session. Up to 16 electrodes will be placed against my scalp and held there by a comfortably fitted headband. The electrodes are flat metal disks about $1 / 4$ inch in diameter. Another may be taped on my forehead above my eye. A drop of electrode cream will be placed under each electrode. This procedure may take up to 45 minutes. Under no circumstances will electricity ever pass from the recording equipment to my body.

During the actual EEG recording session, which may last up to 30 minutes, I understand that I will be asked to perform a simple mental task, such as listening for letters or sounds and signifying by pressing a button.

After the recording session, the EEG technician will remove the electrodes. $\mathrm{He} / \mathrm{Sh}$ will remove most of the electrode cream with water, but I may want to wash my hair when I get home. The cream is not harmful, but it is a little messy.

As part of this study, I may also be asked to fill out brief forms regarding personal information, such as my health, handedness, skills, etc.

This study will provide knowledge about how the brain processes information and where the processing may take place. This knowledge will help clinicians to do a better job recognizing abnormal EEG patterns.

My privacy will be protected during the course of the study. Though the computer disk on which my records are stored may contain a label with my Social Security number, my data will always be labled with a number code available only to Dr. Valentino. I will not be identified in any publication of this study. 
If I am not satisfied with the way the study is performed, I may discuss my complaints with Dr. Valentino or with the Psychology Department Chairperson, Dr. Janet Kulberg (792-2193), anonymously, if I choose. In addition, I may contact the office of the Vice Provost for Research. 70 Lower College Road, University of Rhode Island, Kingston, R.I., telephone: (401) 792-2635.

I have read the Consent Form. My questions have been answered. My signature on this form means that I understand the information and I agree to participate in this study.

Signature Date

Witness Date

Investigator Date 
Grous

\#

Henentegne-

EEG जit: :

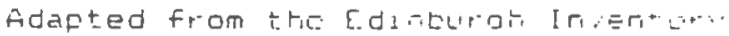

Date

have you eve: had ariv teridericy towsid left-hemdedness

YES $\quad$ NO

Is inyone ir your fami lu left-riended (1.5. Farents. जablings) ?

YES

Nin

If you are ieft-handed. do vou write with ar lriverted hand posture?

YES NU

Filease indicate vour preference 1.7 the lise of rands in the followlrg activities by puttirig + $1 r_{1}$ the grorodriete columr.. Where the preference is so etrorig that rou wolld royer try to lise the siner hand uriless absolutelv forced to. put ++. If in sriv case vou are really indifferent. Fut + in both coilums.

Fiease try to answer all the questions. arrd orly leave a blant if

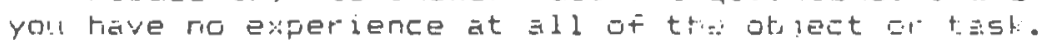

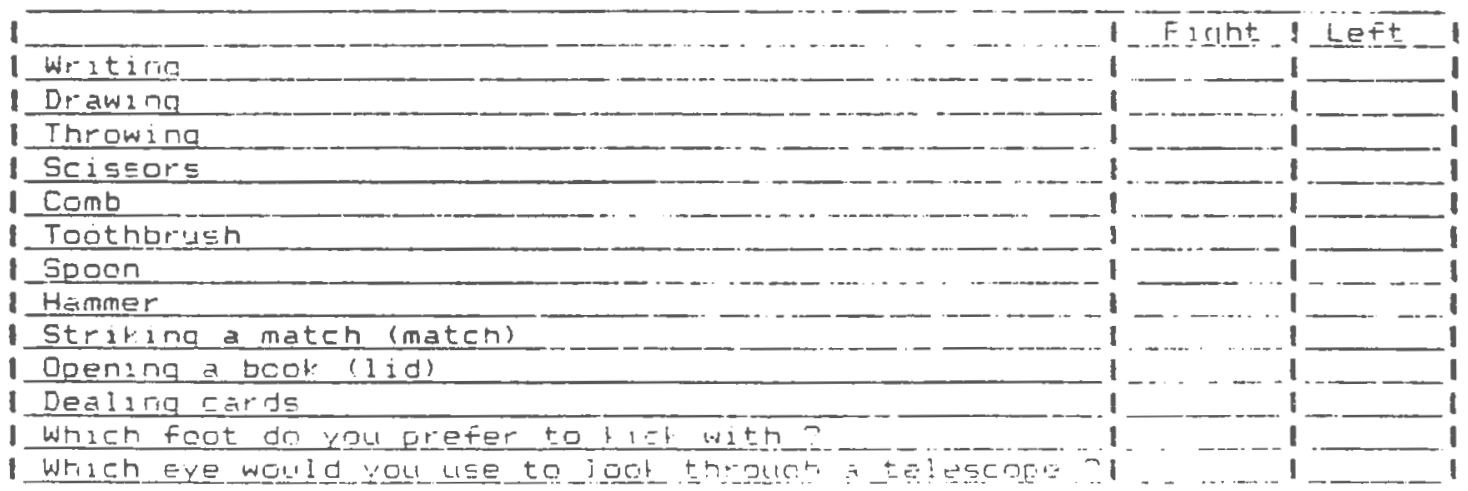


1. Have you ever had a head injury?
a. yes
b. no

If answer to \#t was yes, answer questions 2-6, it no skip to question 7

2. Were you seen in a hospital for your head injury?

a. yes

b. no

3. Approximate date(s) of head injury(s)?

4. Did you lose consciousness during the head injury?

a. yes

b. no

5. Did you have amnesia (can't remember what happened)

for a time before the head injury?

a. yes

Approximately how long in minutes

b. no

6. Did you have amnesia (can't remember what happened)

for a time after the head iniury?

a. yes

Approximately how long in minutes

b. no

7. Have you ever lost consciousness anytime other

than a than head injury?

Please describe

a. yes

b. no

8. Have you ever or anyone in your immediate family ever had a neurological disorder such as epilepsy, Tourette's syndrome, Parkinson's disease or altention deficit disorder?

Please describe

b. no

If answer to \#8 was yes, answer question 9, if no skip to question 10.

9. How far removed from yourself was the relative with a neurological condition?
a. myself
b. sibling
c. parent
d. grandparent
e. auntuncle
a. <4 hours ago
b. $4+$ to 12 hrs
c. $12+$ to 24 hrs
d. more than 1 day
e. never

10. When was your most recent use of of caffeine? 
11. When was your most recent use of of tobacco?
a. $<4$ hours ago
b. $4+$ to 12 hrs
c. $12+$ to 24 hrs
d. more than 1 day
e. never

12. Have you or anyone in your immediate family ever been diagnosed as having attention deficit disorder, dyslexia, or a learning disability?
a. yes
b. no

Please describe

If answer to \#12 was yes. answer question 13, if no skip to question 14.

13. How far removed from yourself was the relative with a neurological condition?
a. myself
b. sibling
c. parent
d. grandparent
e aunituncle

14. Are you currently taking any medications?

a. yes
b. no

If yes, what medication

dosage per day

What do you take this medication for?

15. Have you ever been treated or hospitalized for psychiatric reasons such as depression, schizophrenia, bipolar disorder or anxiety?

a. yes

b. no

16. Has anyone in your immediate family ever been treated or hospitalized for psychiatric reasons such as depression, schizophrenia, bipolar disorder or anxiety?
a. yes
b. no
a. yes

17. Have you ever been treated for drug or alcohol problems?

18. Are you aware of any birthing complications associated with your birth?

a. yes

Please describe

b. no

10 Did vou have anv orolnnaed oeriods of hiah levep as an infant?

a. yes

b. no

20. Have you ever had an EEG before?

a. yes

Why was it ordered?

b. no 
1. Do you feel you are a normal drinker?

1. 2. yes

b. no

2. Do friends or relatives think you are a normal drinker

2. 2. yes

b. no

3. Have you ever attended a meeting of Alcoholics Anonymous(AA)?

3. a. yes

b. no

4. Have you ever lost friends or girlfriends/boyfriends due to your drinking?

4. a. yes

b. no

5. Have you ever gotten into trouble at school or work because of your drinking?

5. a. yes

b. no

6. Have you ever neglected your obligations, your family, or schoolwork for two or more days in a row because of your drinking?

6. a. yes

b. no

7. Have you ever had delirium tremors (DTs), severe shaking, heard voices or seen things that weren't there after heavy d rinking?

7. a. yes

b. no

8. Have you ever gone to anyone for help about your drinking?

8. 2. yes

b. no

9. Have you ever been in a hospital because of drinking

9. a. yes

b. no

10. Have you ever been arrested for drunk driving?

10. a. yes

b. no 
Appendix B.

Table 1. Mean hit rate, reaction time (RT), and false alarm (FA) rate for 22 right handed males during performance of letter, tone, and word tasks using the left hand and the right hand.

\section{Performance}

$$
\text { Hit Rate }(8) \quad \text { RT (in sec) } \quad F A(8)
$$

Task

$\begin{array}{llll}\text { Letter right hand } & 92(7.8) & .63(.07) & 0.45(.60) \\ \text { Letter left hand } & 91(7.5) & .64(.05) & 0.45(.74) \\ \text { Tone right hand } & 61(22.0) & .64(.05) & 3.80(3.4) \\ \text { Tone left hand } & 60(22.0) & .64(.08) & 3.80(3.5) \\ \text { Word right hand } & 43(12.4) & .88(.09) & 1.32(1.5) \\ \text { Word left hand } & 40(14.9) & .89(.10) & 1.11(1.3)\end{array}$


Table 2

Mear absolute power and (SD) for betah, batal, and alpha 100 io ( $N=22$ ) at eight electrode sites for each level of task (tone, letter, word) for the left hand used and the right hiand used.

Beta2

Left Hand Erontal Right Hand Left Hemis Right Hemis Left Hemis Right Hemis

\begin{tabular}{|c|c|c|c|c|}
\hline tone & $.223(.36)$ & $.235(.36)$ & $.249(.35)$ & $.255(.33)$ \\
\hline letter & $.194(.28)$ & $.221(.31)$ & $.245(.40)$ & $.223(.42)$ \\
\hline \multirow[t]{3}{*}{ word } & $.308(43)$ & $.331(.54)$ & $.180(.32)$ & $.216(.46)$ \\
\hline & \multicolumn{4}{|c|}{ Fronto-temporal } \\
\hline & Left Hemis & Right Hemis & Left Hemis & Right Hemis \\
\hline tone & $.571(.48)$ & $.516(.60)$ & $.503(.36)$ & $.551(.36)$ \\
\hline letter & $.301 .(.35)$ & $.444(.37)$ & $.339(.39)$ & $.454(.41)$ \\
\hline \multirow[t]{4}{*}{ พord } & $.500(.45)$ & $.580(.52)$ & $.375(.43)$ & $.453(.38)$ \\
\hline & \multicolumn{4}{|c|}{ Temporal } \\
\hline & \multicolumn{2}{|c|}{ Left Hand } & \multicolumn{2}{|c|}{ Right Hand } \\
\hline & Left Hemis & Right Hemis & Left Hemis & Right kemis \\
\hline tone & $.660(.46)$ & $.627(.53)$ & $.577(.37)$ & $.645(.37)$ \\
\hline letter & $.525(.31)$ & $.543(.41)$ & $.510(.30)$ & $.561(.41)$ \\
\hline \multirow[t]{4}{*}{ word } & $.648(.42)$ & $.635(.51)$ & $.579(.39)$ & $.595(.41)$ \\
\hline & \multicolumn{4}{|c|}{ Temporal-occipital } \\
\hline & \multicolumn{2}{|c|}{ Left Hand } & \multicolumn{2}{|c|}{ Right Hand } \\
\hline & Left Hemis & Right Hemis & Left Hemis & Right Henis \\
\hline tone & $.363(.40)$ & $.312 ! .35 !$ & $.234(-34)$ & $.233(.32)$ \\
\hline letter & $.354(.42)$ & .2701 .301 & $.345(.44)$ & $.235(.27)$ \\
\hline word & $.421(.48)$ & $.341 ! .301$ & $.404(.40)$ & $.288(.22)$ \\
\hline
\end{tabular}

Beta1

Left Hand

Right Hand

Left Hemis Right Hemis Left Henis Right Hemis

tone

$.054(.25)$

$.034(.21)$

$.050(.23)$

$.037(.24)$

letter

$-.002(.21)$

$.039(.30)$

$.559(.32)$

$.022(.32)$

word

.0471 .29

$.006(.37)$

$-.031: .231$

$.002(.32)$

Fronto-temporal

Left Hand

Right Hand

Left Hemis Right Hemis Left Hemis Right Hemis

\begin{tabular}{|c|c|c|c|c|}
\hline tone & $.285(.33)$ & $\therefore 641 . \therefore 2\}$ & $.956(.21)$ & $.280(.33)$ \\
\hline letter & $.173(.25)$ & $\therefore 411.31$ & $.14 \div(.25)$ & $.240(.37)$ \\
\hline word & $.254(.30)$ & .2791 .251 & .151 i.20) & $.235(.30)$ \\
\hline
\end{tabular}


Table 2 continued.

Left Hand Temporal Right Hand Left Hemis Right Heris Left Hemis Right Hemis

$\begin{array}{lllll}\text { tone } & .432(.29) & .443(.40) & .452(.23) & .453(.30) \\ \text { letter } & .405(.22) & .417(.30) & .421(.20) & .427(.33) \\ \text { word } & .482(.27) & .445(.35) & .434(.23) & .431(.31) \\ & \text { Left Hemis } & \text { Right Hemis } & \text { Left Heris } & \text { Right Hemis } \\ & .316(.29) & .241(.24) & .253(.25) & .196(.25) \\ \text { tone } & .274(.30) & .217(.21) & .313(.31) & .252(.22) \\ \text { letter } & .378(.36) & .255(.23) & .313(.21) & .230(.19) \\ \text { word } & & & \end{array}$

Alpha

Left Hand Right Hand

Left Henis Right Hemis Left Hemis Right Hemis

\begin{tabular}{|c|c|c|c|c|}
\hline tone & $.412(.19)$ & $.433(.18)$ & $.408(.20)$ & $.450(.21)$ \\
\hline letter & $.387(.19)$ & $.438(.18)$ & $.412(.20)$ & $.474(.28)$ \\
\hline \multirow[t]{3}{*}{ word } & $.444(.21)$ & $.507(.26)$ & $.4015(.21)$ & $.462(.22)$ \\
\hline & \multicolumn{4}{|c|}{ Fronto-tenporal } \\
\hline & Left Hemis & Right Hemis & Left Henis & Right Hemis \\
\hline tone & $.637(.25)$ & $.642(.33)$ & $.5000(.00)$ & $.682(.07)$ \\
\hline letter & $.536(.27)$ & $.636(.34)$ & $.1513(.23)$ & $.705(.34)$ \\
\hline \multirow[t]{4}{*}{ word } & $.563(.25)$ & $.532(.35)$ & $.518(.29)$ & $.522(.33)$ \\
\hline & \multicolumn{4}{|c|}{ Temporal } \\
\hline & Left & Hand & Righ & and \\
\hline & Left Hemis & Right Hemis & Left Hemis & Right Hemis \\
\hline tone & $1.178(.38)$ & $1.220(.50)$ & $1.165(.09)$ & $1.232(.11)$ \\
\hline letter & $1.126(.42)$ & $1.212(.52)$ & $1.189(.43)$ & $1.262(.53)$ \\
\hline \multirow[t]{3}{*}{ word } & $1.091(.41)$ & $1.195(.49)$ & $1.043(.42)$ & $1.130(.51)$ \\
\hline & \multicolumn{4}{|c|}{ Temporal-occipital } \\
\hline & Left Hemis & $\begin{array}{l}\text { Hand } \\
\text { Right Hemis }\end{array}$ & $\begin{array}{l}\text { Righ } \\
\text { Left Hemis }\end{array}$ & Right Hemis \\
\hline tone & $1.079(.49)$ & $1.026(.43)$ & $1.077(.47)$ & $1.032(.44)$ \\
\hline letter & $1.117(.49)$ & $1.015(.43)$ & L. $157(.47)$ & $1.032(.42)$ \\
\hline word & $(.1173(.47)$ & $.390(.43)$ & $1.079(.47)$ & $.271(.43)$ \\
\hline
\end{tabular}


Tat.le $\overline{3}$.

Mean absolute rower and (SD) for beta2, betal, and alpha log 10 (N=22) at eight electrode sites for a baseline resting condition.

Beta2

$\begin{array}{lc}\text { Left Hemisisphere } & \text { Right Hemisphere } \\ .091(.39) & .089(.33) \\ .232(.36) & .337(.33) \\ .422(.36) & .440(.40) \\ .208(.35) & .151(.23)\end{array}$

Beta1

Left Hemisisphere
$-.050(.29)$
$.134(.21)$
$.408(.24)$
$.260(.29)$

Right Hemisphere

$-.050(.24)$

$.200(.34)$

$.425(.34)$

$.229(.23)$

Alpha

Left Herisphere

$$
\begin{array}{r}
.413(.23) \\
.712(.32) \\
1.237(.46) \\
1.112(.53)
\end{array}
$$

Right Hemisphere
$.462(.24)$
$.769(.40)$
$1.254(.59)$
1. $029(.47)$ 
Figure 1. Beta $2 \log _{10}$ for right handed males $(N=22)$ at 4 brain regions under conditions of tone, letter, and word, with the left hand used and the right hand used and in the left and right hemisphere. 

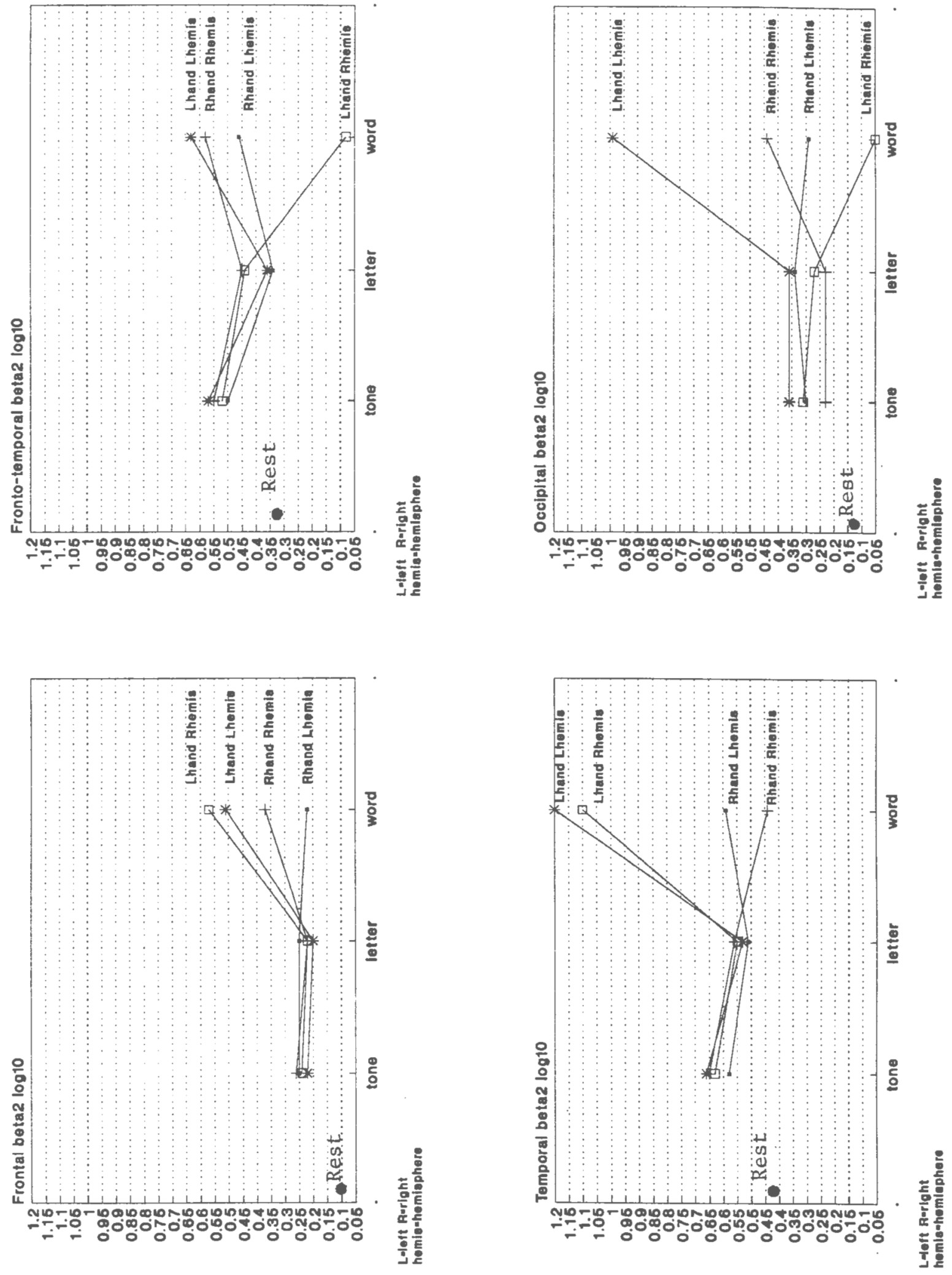
Figure 2. Beta2 $\log _{10}$ for right handed males $(N=22)$ at FT region under conditions of tone, letter, and word and left and right hemispheres. 


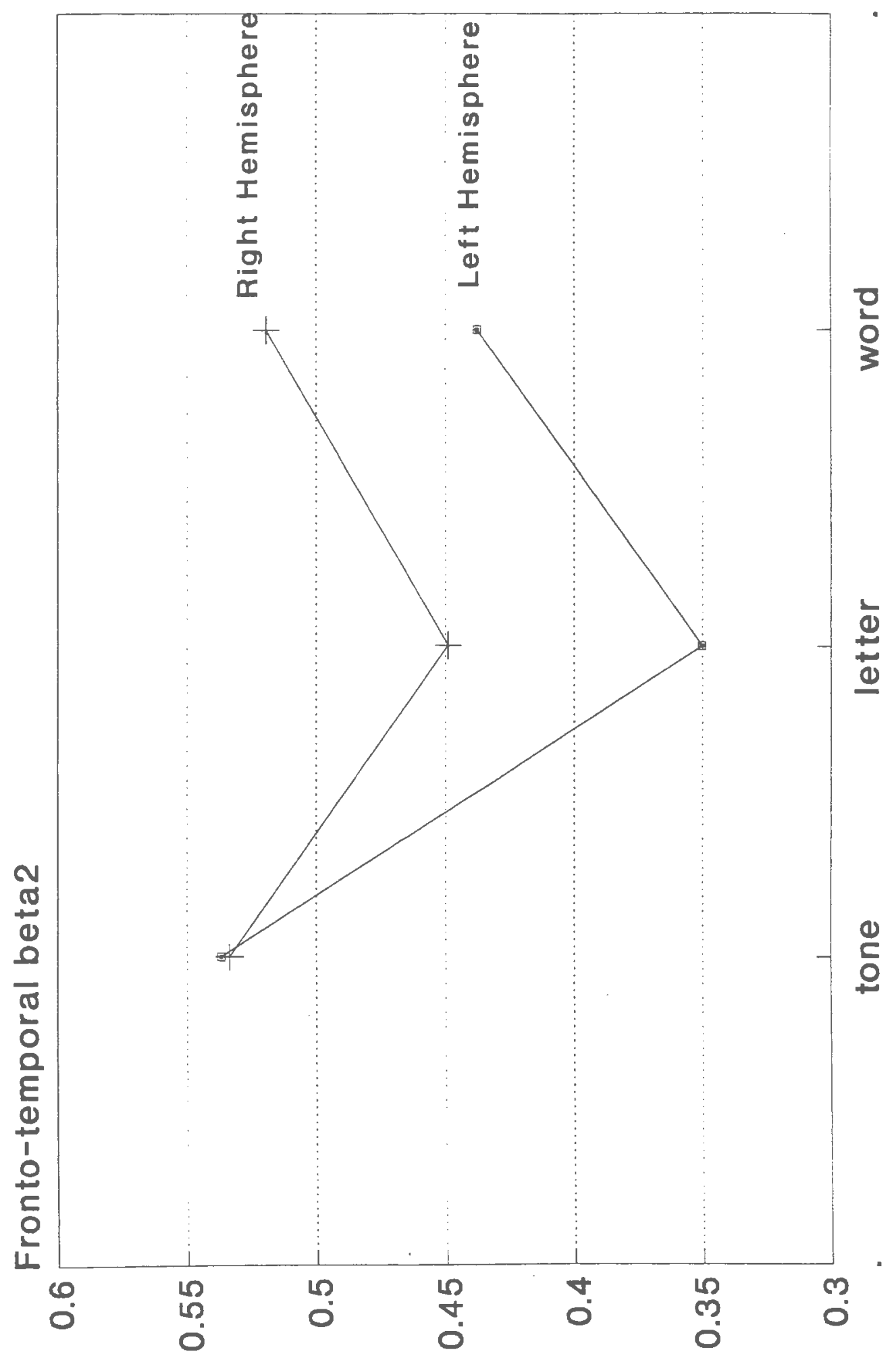


Figure 3. Alpha $\log _{10}$ for right handed males $(N=22)$ at 4 brain regions under conditions of tone, letter, and word, with the left hand used and the right hand used and in the left and right hemisphere. 

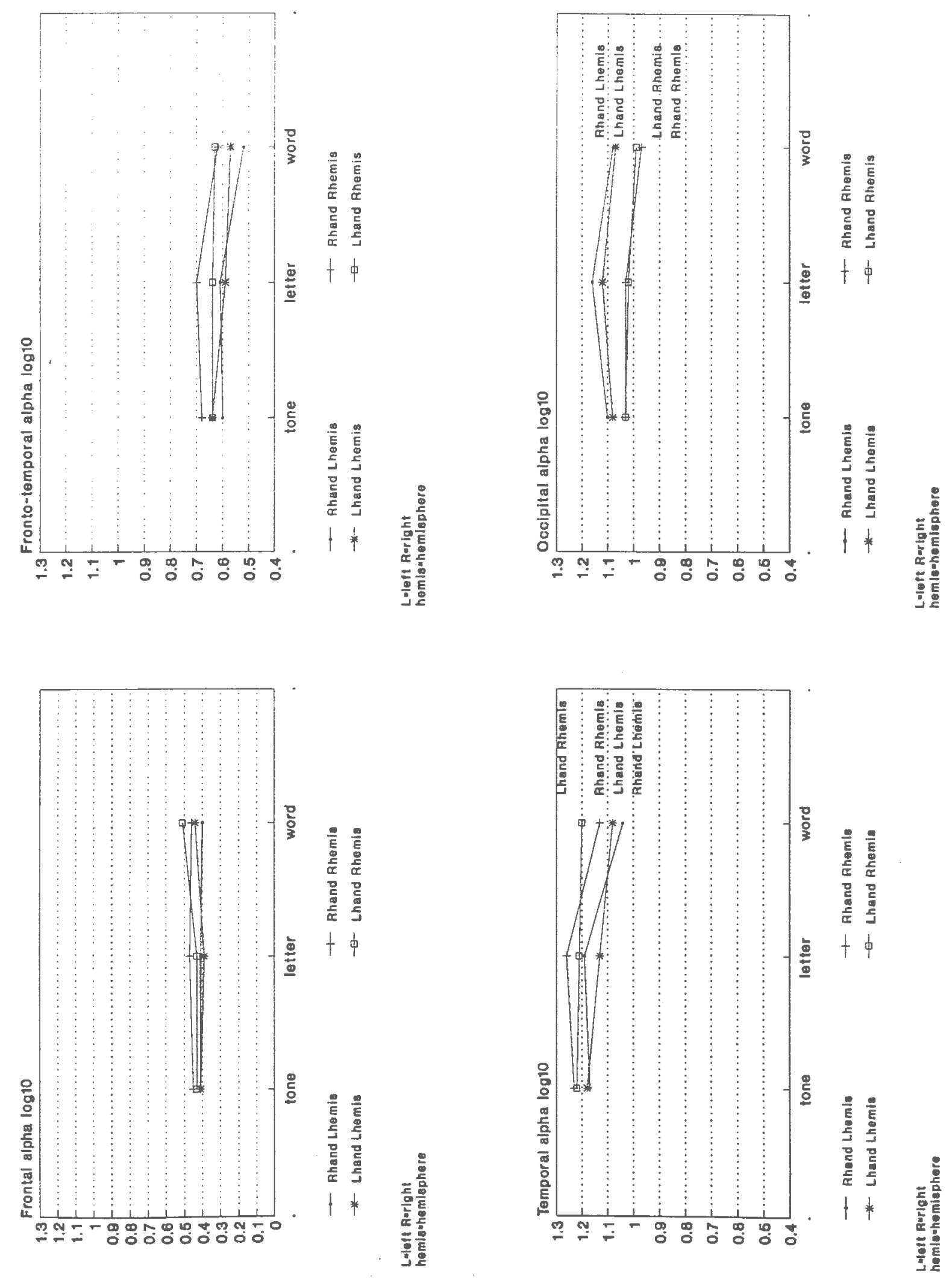
Figure 4. Alpha $\log _{10}$ for right handed males $(N=22)$ at FT region under conditions of tone, letter, and word and in the left and right hemispheres. 


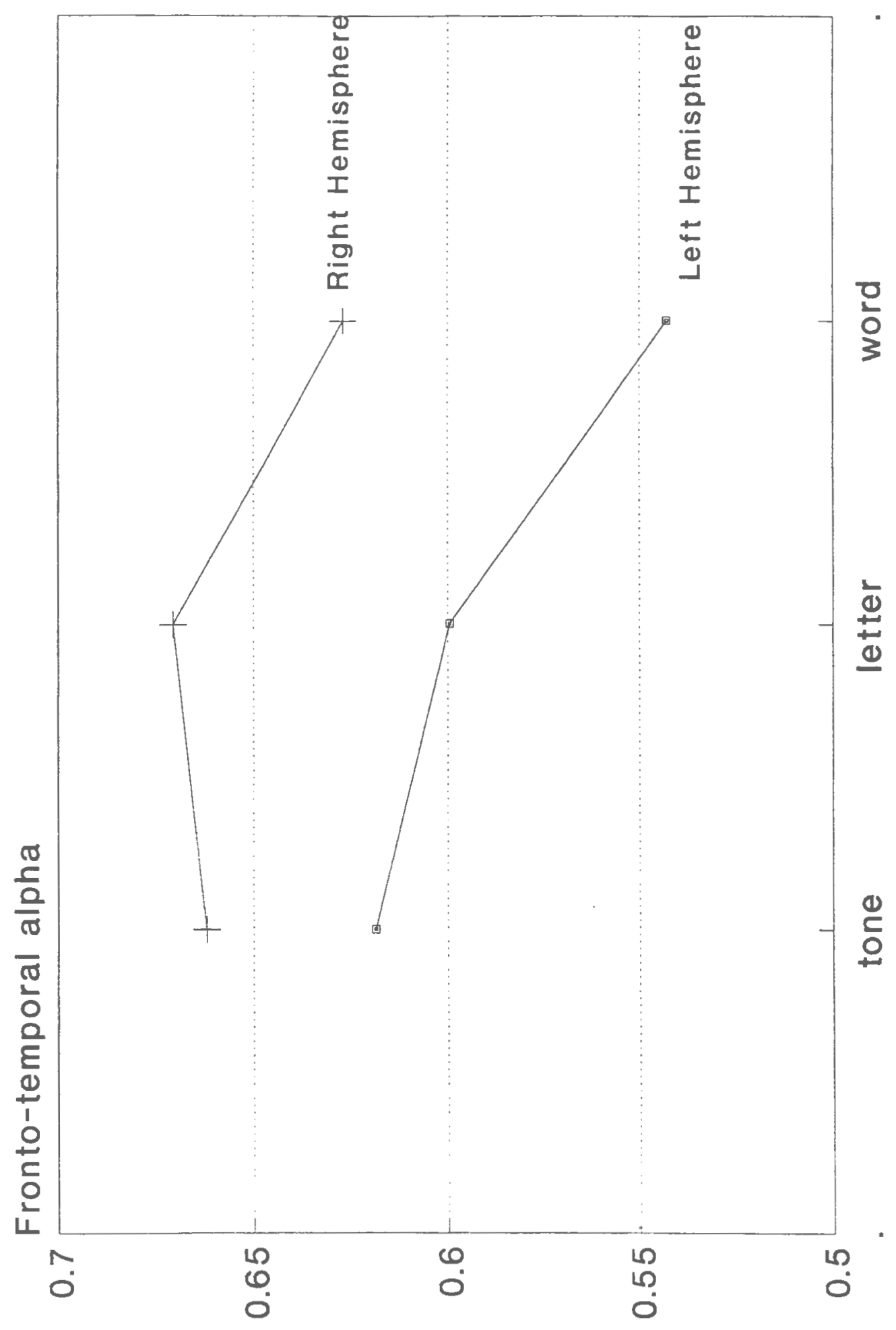


Figure 5. Alpha $\log _{10}$ for right handed males $(N=22)$ at $T$ region under conditions of tone, letter, and word and in the left and right hemispheres. 


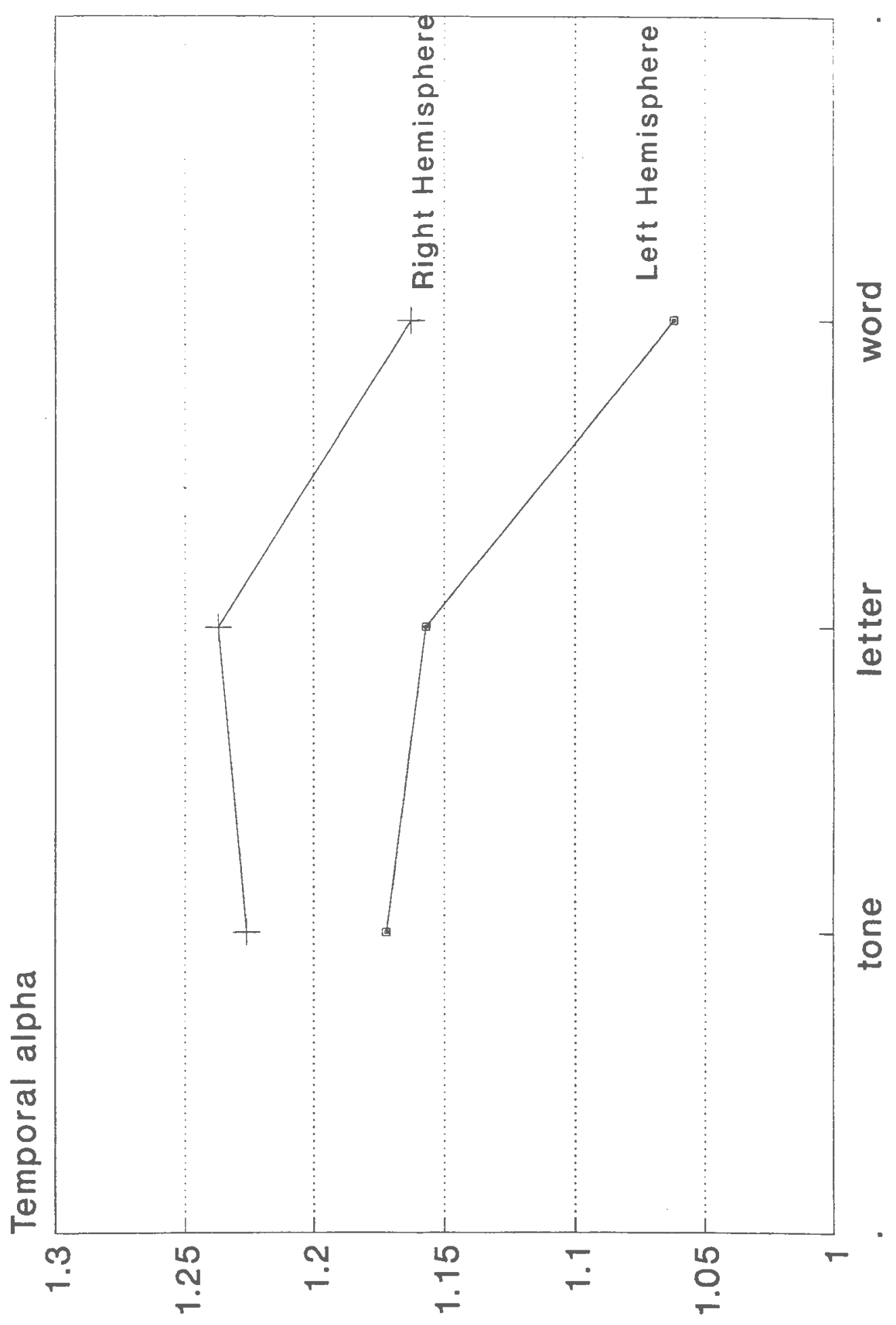


Figure 6. Alpha $\log _{10}$ for right handed males $(N=22)$ at FT region during left hand and right hand performance and in the left and right hemispheres. 


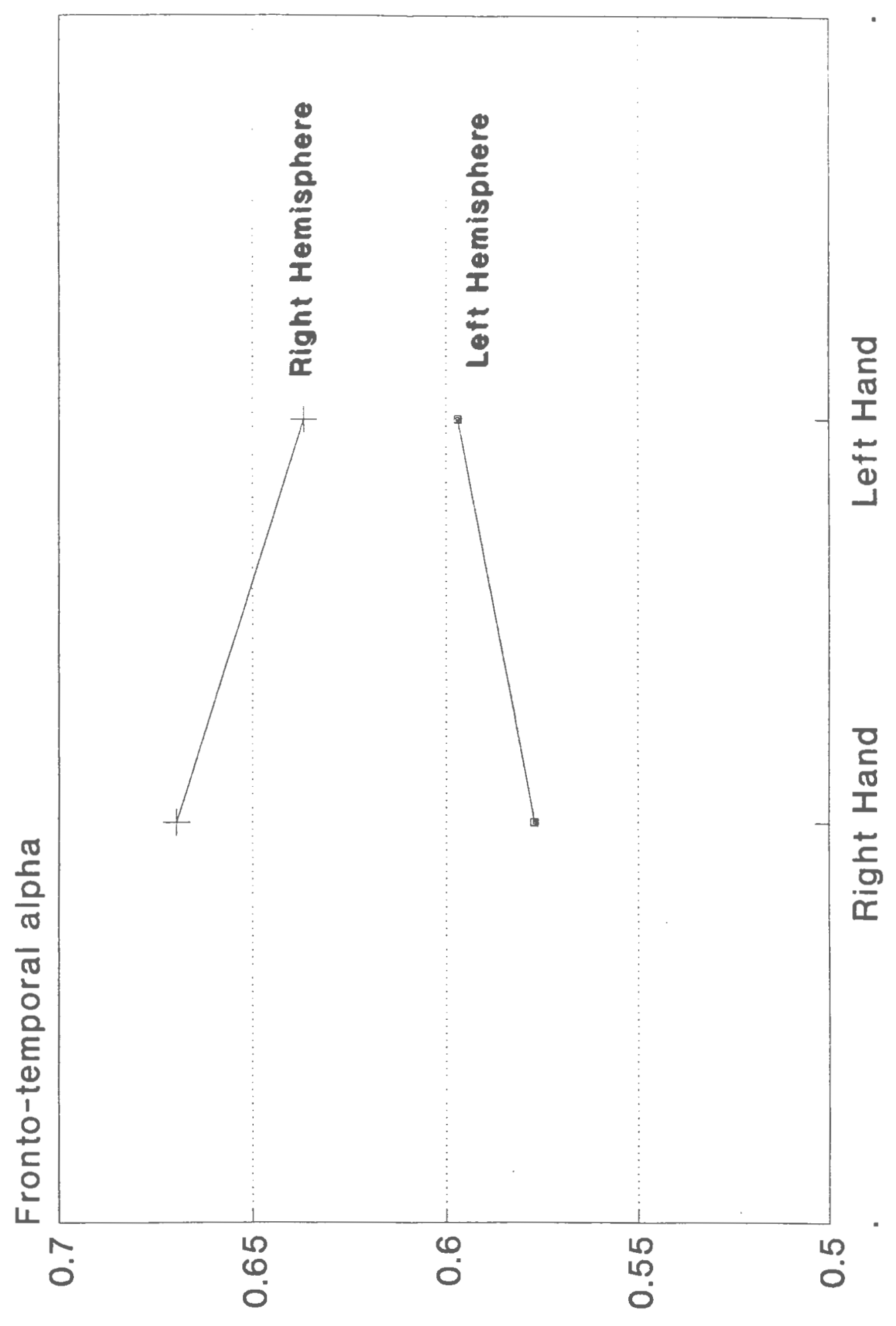




\section{Bibliography}

Arruda, J.E. (1994). Confirmatory factor analyses of quantified electroencephalogram measured during

a continuous performance test: A confirmation of neuro-functional systems. Doctoral

Dissertation, University of Rhode Island.

Autret, A., Auvert, L., Laffont, F., Larmande, P. (1985).

Electroencephalographic spectral power and

lateralized motor activities.Electoencephalography

and Clinical Neurophysiology, 60, 228-236.

Butler, S., Glass, A. (1974). Asymmetries in the

electroencephalogram associated with cerebral

dominance. Electoencephalography and clinical

Neurophysiology, 36, 481-491.

DeToffel, B., Autret, A., Markabi, S., Roux, S. (1990).

Influence of lateralized sensorimotor and

neuropsychological activities on

electroencephalographic spectral power.

Electoencephalography and Clinical Neurophysiology, 75, 200-206.

Empson, J.A.C. (1982). Slow potentials preceding vocalization. Biological Science, 14, 271-276. 
Galin, D., Ornstein, R., Herron, J., \& Johnstone, J. (1982). Sex and handedness differences in EEG measures of hemispheric specialization. Brain and Language, 16, 19-55.

Friedman,A. \& Polson, M.C. (1988). Dividing attention between the hands and the head: performance tradeoffs between rapid finger tapping and verbal memory. J of Experimental Psychology 14(1):60-68.

Gevins, A.S., Schaffer, R.E. (1980). A critical review of electroencephalographic (EEG) correlates of higher cortical functions. C.R.C. Critical Review Bioengineering, 4 , 113-164. Gold,S. (1992). The effects of handedness and hand used on EEG during an auditory continuous performance test. Master's Thesis, University of Rhode Island. Kinsbourne, M., Hiscock, M. (1983). Asymmetries of dualtask performance. In J.B. Hellige (Ed.). Cerebral hemisphere asymmetry: Method, theory, and application. 255-334. New York: Praeger. Kristeva, R., Keller, E., Deeke, L., \& Kornhuber, H. (1979). Cerebral potentials preceding right and left unilateral and simultaneous bilateral finger movements. Electoencephalography and clinical Neurophysiology, 47, 229-238. 
Lauter, J.L. (1992). Processing asymmetries for complex sounds: Comparisons between behavioral ear advantages and electrophysiological asymmetries based on quantitative electroencephalography. Brain and Cognition 19:1-20.

Oldfield, R.C. (1971). The assessment and analysis of handedness: The Edinburgh Inventory. Neuropsychologia, 9, 97-114. Papanicolaou, A.C., Loring, D.W., Deutsch, G., \& Eisenberg, H. (1986). Task-related EEG asymmetries: A comparison of alpha blocking and beta enhancement. International Journal of Neuroscience. 30:81-85. Petersen, S.E., Fox, P.T., Posner, M.I., Mintun, M., Raichle, M.E. (1989). Positron emission tomographic studies of the processing of single words. Journal of Cognitive Neuroscience. $1(2): 153-170$. Provins, K.A., Cunliffe, P. (1972). The relationship between EEG activity and handedness. Cortex, 8, 136146 .

Ray, W.J., \& Cole, H. (1985). EEG alpha activity reflects attentional demands, and beta activity reflects emotional and cognitive processes. Science. 228:750752 . 
Rebert, C., Mahoney, R. (1978). Functional crebral asymmetry and performance III. Reaction time as a function of task, hand, sex, and EEG asymmetry. Psychophysiology, 15, 9-16. Sidtis, J. (1980). On the nature of the cortical function underlying right hemisphere auditory perception. Neuropsychologia. 18:321-330.

Sidtis, J., \& Bryden, M.P. (1978). Asymmetrical perception of language and music: Evidence for independent processing strategies. Neuropsychologia. $\underline{16}: 627-632$.

Valentino, D.A., Arruda, J.E., Gold, S.M. (1993) Comparison of QEEG and response accuracy in good vs. poorer performers during a vigilance task. Intern $\underline{J}$ Psychophysiology. 15:123-133.

Weiler, M. (1992). A measurement model for spectral analyzed EEG. Doctoral Dissertation, University of Rhode Island. 